\title{
Genome-wide association study of nevirapine hypersensitivity in a malawian HIV-infected population
}

\author{
Daniel Carr ${ }^{1 *}$, Stephane Bourgeois ${ }^{2}$, Mas Chaponda ${ }^{1}$, Elena Cornejo Castro ${ }^{1}$, Panos Deloukas ${ }^{2}$, Munir Pirmohamed ${ }^{1}$ \\ From 6th Drug Hypersensitivity Meeting (DHM 6) \\ Bern, Switzerland. 9-12 April 2014
}

The non-nucleoside reverse transcriptase inhibitor nevirapine is used in the treatment of HIV in many developing countries. Its use is associated with occurrence of hypersensitivity in 6-10\% of patients. This hypersensitivity can manifest as a number of phenotypes which include the severe skin blistering reactions Stevens Johnson syndrome (SJS) and toxic epidermal necrolysis (TEN). The aim was to undertake a genome wide association study (GWAS) in order to identify genetic variants associated with predisposition to nevirapine-induced hypersensitivity. A total of 333 nevirapine-exposed (151 hypersensitive and 182 tolerant), HIV-infected Malawian adults were genotyped for 826,551 genotyped SNPs using the Illumina HumanOmni1-Quad_v1 chip. A replication cohort of 62 hypersensitive and 59 tolerant patients from Malawi and Uganda was genotyped for 40 SNPs statistically significantly associated with a hypersensitive phenotype in the main cohort $(\mathrm{p}<5 \times 10-5)$ using the Sequenom iPLEX platform or TaqMan allelic discrimination. Logistic regression analysis identified 40 statistically significant SNP signals associated with a nevirapine hypersensitivity phenotype. Only 1 SNP association signal (in the HLA-C locus, associated with SJS/TEN) was statistically significant in both our main discovery $(=1.48 \times 10-6)$ and enriched replication cohort (38 cases and 59 controls) ( $\mathrm{p}=9.6 \times 10-5)$. Meta-analysis determined the odds ratio as 5.17 $(\mathrm{p}=2.61 \times 10-10)$. Data suggest this SNP to be a strong proxy for HLA-C*04:01 carriage (96\% co-occurrence). We have confirmed that, in a sub-Saharan African population, HLA-C* 04:01 carriage confers a significant risk for nevirapine-induced SJS_TEN though not to less severe hypersensitivity phenotypes. No other significant high penetrance genetic risk factors were identified.

'University of Liverpool, Molecular and Clinical Pharmacology, UK

Full list of author information is available at the end of the article

\section{Authors' details}

${ }^{1}$ University of Liverpool, Molecular and Clinical Pharmacology, UK.

${ }^{2}$ Queen Mary University London, William Harvey Research Institute, UK.

Published: 18 July 2014

doi:10.1186/2045-7022-4-S3-P125

Cite this article as: Carr et al:: Genome-wide association study of nevirapine hypersensitivity in a malawian HIV-infected population. Clinical and Translational Allergy 2014 4(Suppl 3):P125.
Submit your next manuscript to BioMed Central and take full advantage of:

- Convenient online submission

- Thorough peer review

- No space constraints or color figure charges

- Immediate publication on acceptance

- Inclusion in PubMed, CAS, Scopus and Google Scholar

- Research which is freely available for redistribution
() Biomed Central 